\title{
Capecitabine Plus Oxaliplatin Combination Therapy for Basal Cell Carcinoma
}

\author{
Jiyoung Rhee, Jaemin Jo, Sang-Hoon Han, Jung-Mi Kwon \\ Division of Hematology-Oncology, Department of Internal Medicine, Jeju National University Hospital, Jeju, Korea
}

\begin{abstract}
No effective systemic chemotherapy is well-established in basal cell carcinoma. We report a case with three simultaneous malignancies: colon cancer, basal cell carcinoma, and smoldering multiple myeloma. The patient was treated with capecitabine and oxaliplatin after surgery for colon cancer. Surprisingly, he achieved a complete response for basal cell carcinoma. This is the first report of this chemotherapy regimen in basal cell carcinoma. This finding suggests that combination capecitabine and oxaliplatin can be a treatment option for patients unable to receive local therapy. (Ann Dermatol 31(2) 201 203, 2019)
\end{abstract}

\section{-Keywords-}

Basal cell carcinoma, Capecitabine, Chemotherapy, Oxaliplatin

\section{INTRODUCTION}

Basal cell carcinoma (BCC) of skin is most commonly diagnosed malignancy in many countries, especially in those with a large Caucasian population ${ }^{1}$. A recent analysis shows that the incidence of BCC has rapidly increased

Received January 5, 2018, Revised February 9, 2018, Accepted for publication February 12, 2018

Corresponding author: Jiyoung Rhee, Division of Hematology-Oncology, Department of Internal Medicine, Jeju National University Hospital, 15 Aran 13-gil, Jeju 63241, Korea. Tel: 82-64-717-1590, Fax: 82-64-717-1402, E-mail: splendor97@gmail.com

ORCID: https://orcid.org/0000-0002-7787-4852

This is an Open Access article distributed under the terms of the Creative Commons Attribution Non-Commercial License (http://creativecommons. org/licenses/by-nc/4.0) which permits unrestricted non-commercial use, distribution, and reproduction in any medium, provided the original work is properly cited.

Copyright (c) The Korean Dermatological Association and The Korean Society for Investigative Dermatology in South Korea, although it is still lower than in Western countries $^{2}$. Because BCC rarely metastasizes, treatment is focused on local control ${ }^{1}$. However, in certain populations, local treatment is not feasible and systemic treatment is needed, due to a patient's condition or tumor characteristics, including location, burden, and aggressiveness ${ }^{3}$. However, a standard chemotherapy is not established for BCC and only case reports serve to support various regimens. Therefore, we report here the first case of BCC treated with capecitabine and oxaliplatin combination therapy. The study was approved by the Institutional Review Board of the Jeju National University Hospital (IRB no. JEJUNUH 2017-08-003). We received the patient's consent form about publishing all photographic materials.

\section{CASE REPORT}

In February 2014, a 57-year-old man visited our out-patient clinic to discuss adjuvant chemotherapy for colon cancer. He had undergone anterior resection on a descending colon cancer in January 2014 and was diagnosed with American Joint Committee on Cancer stage IIIB (T4aN1a) moderately differentiated adenocarcinoma in the colon. Because of the risk of recurrence, we recommended adjuvant chemotherapy (capecitabine and oxaliplatin [XELOX]). After the first cycle of XELOX, we detected a $1-\mathrm{cm}$ crusted ulcerative lesion with an elevated margin on his upper lip, with a vermillion border. He said the lesion had appeared a year prior and continued to grow (Fig. 1A). We obtained a punch biopsy from the skin lesion, and he was diagnosed with BCC in histopathologic examination (Fig. 2). No additional lesions were found in a skin exam.

We consulted a surgeon for treatment of high risk BCC, and he recommended radiation therapy. We believe this 

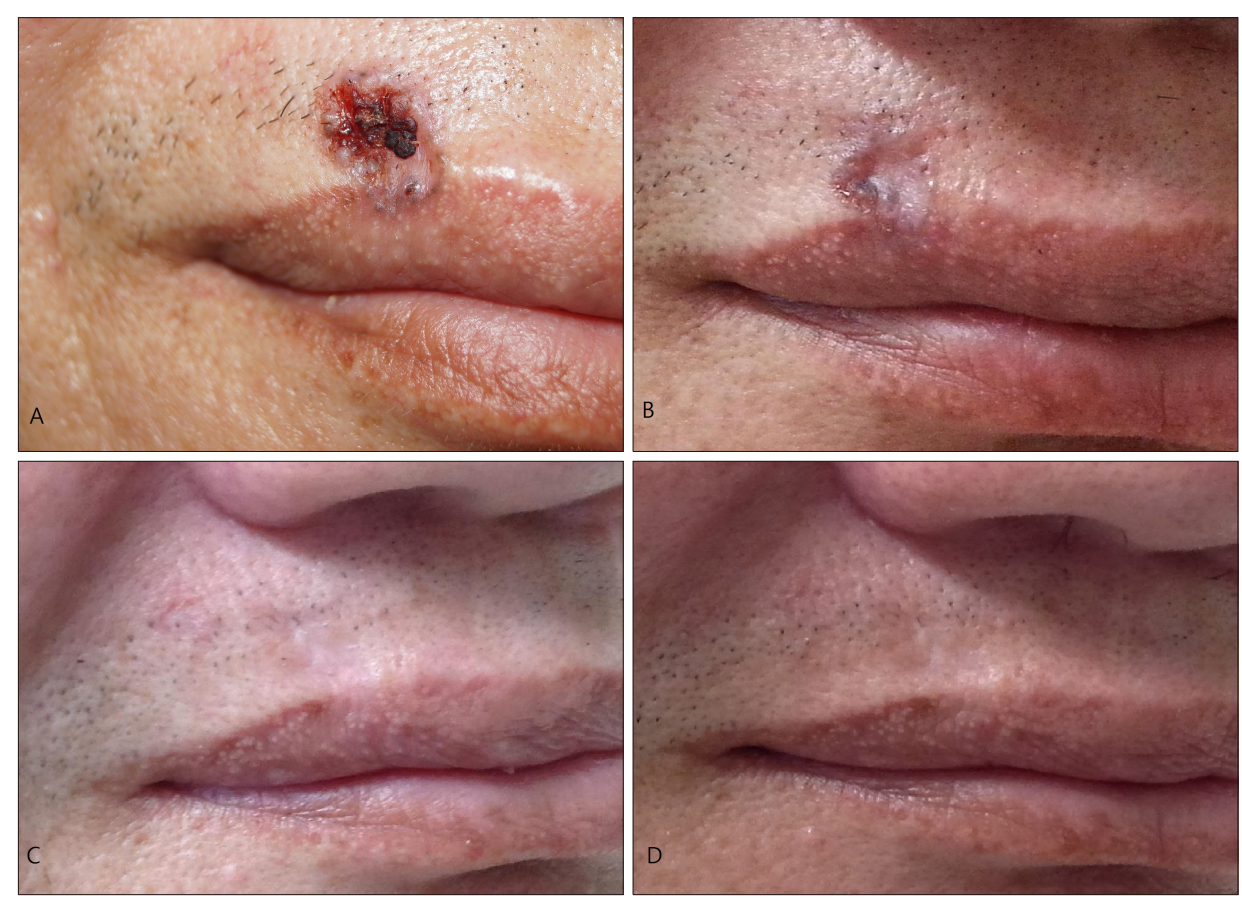

Fig. 1. Serial changes of basal cell carcinoma skin lesion. (A) Before punch biopsy. (B) During XELOX chemotherapy (after 4 cycles). (C) After completion of XELOX chemotherapy (after 8 cycles). (D) Scarring at the time of three years and one month after XELOX chemotherapy.

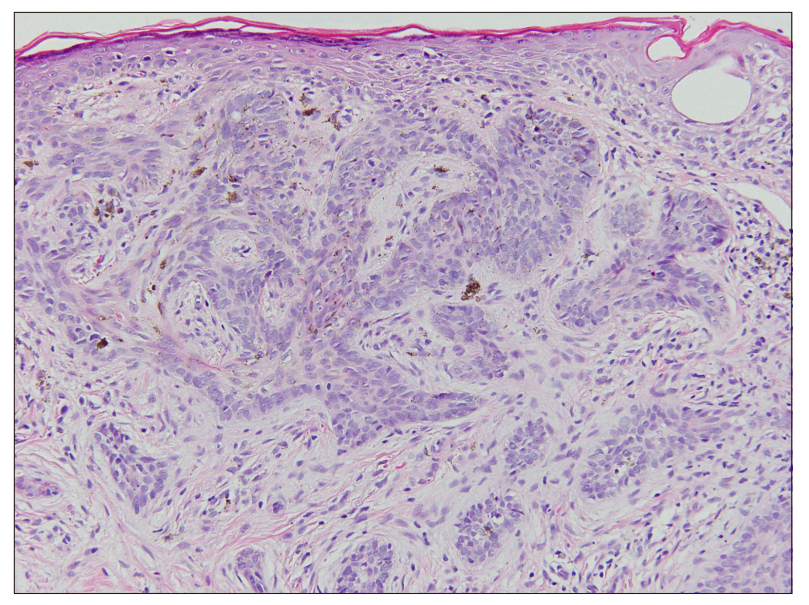

Fig. 2. Microscopic findings of basal cell carcinoma $(\mathrm{H} \& \mathrm{E}$, $\times 200$ ).

recommendation was due to the tumor location and underlying comorbidities, including a history of right middle cerebral artery infarction, diabetes mellitus, asymptomatic myeloma, and colon cancer. However, the patient refused treatment for BCC at that time and postponed the radiation therapy. During discussion of BCC treatment, he continued to receive the XELOX regimen for colon cancer and we found the BCC lesion was improved (Fig. 1B). However, systemic chemotherapy is not the standard treatment for localized BCC. Therefore, after completion of adjuvant XELOX therapy (8 cycles over 6 months), we recommended the radiation therapy for the BCC lesion to the pa- tient again. But he continuously refused the treatment. While he delayed radiation therapy for BCC, the crusted ulcerative tumor lesion gradually normalized, leaving only scarring (Fig. 1C). At his most recent visit, in September 2017, he had no evidence of BCC recurrence (Fig. 1D).

\section{DISCUSSION}

Systemic treatment of BCC has mainly been reported in a small number of patients with metastatic or advanced disease $^{3,4}$. The limited findings of systemic treatment may be due to the high success rate of local treatment ${ }^{1}$. However, research for systemic treatment of BCC is essential when considering the increasing incidence of BCC world-wild, the existence patients who are not candidates for local treatment and the lack of improvement in metastatic BCC survival since the $1980 \mathrm{~s}^{3-5}$.

Since a 1978 phase I II clinical trial for a reported cisplatin response in metastatic BCC, there have been case studies on systemic chemotherapy in BCC with cisplatin containing regimens, combination with 5-FU, bleomycin, doxorubicin, methotrexate, and other regimens ${ }^{3,4,6,7}$. However, only platinum-based chemotherapy has been shown to have some efficacy in BCC and no randomized clinical trial have been conducted ${ }^{3,6}$. Additionally, vismodegib, an inhibitor of the hedgehog pathway signal transducer protein Smoothened, recently showed a response in BCC, but it is not approved in some countries and is costly with limited evidence of clinical benefit ${ }^{8-11}$. Although the XELOX 
regimen in this report was not administered for BCC treatment, but was used for colon cancer treatment, this is the first case report of BCC chemotherapy with capecitabine and oxaliplatin. Notably this treatment achieved a complete response in BCC. Because this regimen is widely used for other solid tumors as an alternative to 5-FU and cisplatin to reduce the inconvenience of infusion and potential toxicities (e.g., renal toxicity and emesis), this therapy is known to be well tolerability and toxicity is manageable $\mathrm{e}^{12-14}$. And previous several reports suggested that low-dose capecitabine $\left(500 \sim 1,500 \mathrm{mg} / \mathrm{m}^{2}\right.$ per day for 14 days of a 21-day cycle) has a chemopreventive effect for basal cell carcinoma, squamous cell carcinoma, and actinic keratosis in solid organ transplant recipients who have higher incidence of nonmelanoma skin cancer than the general population ${ }^{15-17}$. Considering these findings, capecitabine and oxaliplatin combination therapy should be studied as treatment for BCC patient who require a systemic chemotherapy option.

\section{CONFLICTS OF INTEREST}

The authors have nothing to disclose.

\section{ORCID}

Jiyoung Rhee, https://orcid.org/0000-0002-7787-4852

Jaemin Jo, https://orcid.org/0000-0002-2145-9721

Sang-Hoon Han, https://orcid.org/0000-0003-0976-9134

Jung-Mi Kwon, https://orcid.org/0000-0002-8968-0887

\section{REFERENCES}

1. Rubin Al, Chen EH, Ratner D. Basal-cell carcinoma. N Engl J Med 2005;353:2262-2269.

2. Oh $\mathrm{CM}$, Cho $\mathrm{H}$, Won $\mathrm{Y}$, Kong $\mathrm{HJ}$, Roh $\mathrm{YH}$, Jeong $\mathrm{KH}$, et al. Nationwide trends in the incidence of melanoma and non-melanoma skin cancers from 1999 to 2014 in South Korea. Cancer Res Treat 2018;50:729-737.

3. Moeholt K, Aagaard H, Pfeiffer P, Hansen O. Platinum-based cytotoxic therapy in basal cell carcinoma--a review of the literature. Acta Oncol 1996;35:677-682.

4. McCusker M, Basset-Seguin N, Dummer R, Lewis K,
Schadendorf D, Sekulic A, et al. Metastatic basal cell carcinoma: prognosis dependent on anatomic site and spread of disease. Eur J Cancer 2014;50:774-783.

5. Leiter U, Eigentler T, Garbe C. Epidemiology of skin cancer. Adv Exp Med Biol 2014;810:120-140.

6. Ganti AK, Kessinger A. Systemic therapy for disseminated basal cell carcinoma: an uncommon manifestation of a common cancer. Cancer Treat Rev 2011;37:440-443.

7. Salem P, Hall SW, Benjamin RS, Murphy WK, Wharton JT, Bodey GP. Clinical phase I-II study of cis-dichloro-diammineplatinum(II) given by continuous Iv infusion. Cancer Treat Rep 1978;62:1553-1555.

8. Cirrone F, Harris CS. Vismodegib and the hedgehog pathway: a new treatment for basal cell carcinoma. Clin Ther 2012;34:2039-2050.

9. Aggarwal A, Fojo T, Chamberlain C, Davis C, Sullivan R. Do patient access schemes for high-cost cancer drugs deliver value to society?-lessons from the NHS Cancer Drugs Fund. Ann Oncol 2017; 28:1738-1750.

10. Sekulic A, Migden MR, Oro AE, Dirix L, Lewis KD, Hainsworth JD, et al. Efficacy and safety of vismodegib in advanced basal-cell carcinoma. N Engl J Med 2012;366: 2171-2179.

11. Poggi L, Kolesar JM. Vismodegib for the treatment of basal cell skin cancer. Am J Health Syst Pharm 2013;70:1033-1038.

12. Arkenau HT, Arnold D, Cassidy J, Diaz-Rubio E, Douillard JY, Hochster H, et al. Efficacy of oxaliplatin plus capecitabine or infusional fluorouracil/leucovorin in patients with metastatic colorectal cancer: a pooled analysis of randomized trials. J Clin Oncol 2008;26:5910-5917.

13. Cunningham D, Starling N, Rao S, Iveson T, Nicolson $M$, Coxon $\mathrm{F}$, et al. Capecitabine and oxaliplatin for advanced esophagogastric cancer. N Engl J Med 2008;358:36-46.

14. Berk V, Ozdemir N, Ozkan M, Aksoy S, Turan N, Inal A, et al. XELOX vs. FOLFOX4 as second line chemotherapy in advanced pancreatic cancer. Hepatogastroenterology 2012; 59:2635-2639.

15. Endrizzi BT, Lee PK. Management of carcinoma of the skin in solid organ transplant recipients with oral capecitabine. Dermatol Surg 2009;35:1567-1572.

16. Endrizzi B, Ahmed RL, Ray T, Dudek A, Lee P. Capecitabine to reduce nonmelanoma skin carcinoma burden in solid organ transplant recipients. Dermatol Surg 2013;39:634-645.

17. Jirakulaporn T, Endrizzi B, Lindgren B, Mathew J, Lee PK, Dudek AZ. Capecitabine for skin cancer prevention in solid organ transplant recipients. Clin Transplant 2011;25:541-548. 